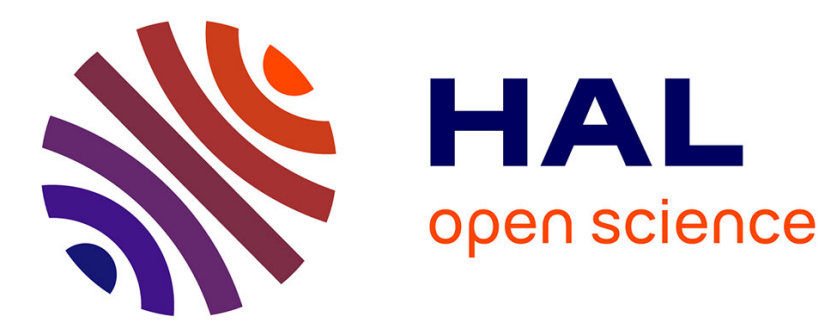

\title{
Network theory-based analysis of risk interactions in large engineering projects
}

\author{
Chao Fang, Franck Marle, Enrico Zio, Jean-Claude Bocquet
}

\section{To cite this version:}

Chao Fang, Franck Marle, Enrico Zio, Jean-Claude Bocquet. Network theory-based analysis of risk interactions in large engineering projects. Reliability Engineering and System Safety, 2012, 10.1016/j.ress.2012.04.005 . hal-01219421

\section{HAL Id: hal-01219421 \\ https://hal.science/hal-01219421}

Submitted on 22 Oct 2015

HAL is a multi-disciplinary open access archive for the deposit and dissemination of scientific research documents, whether they are published or not. The documents may come from teaching and research institutions in France or abroad, or from public or private research centers.
L'archive ouverte pluridisciplinaire HAL, est destinée au dépôt et à la diffusion de documents scientifiques de niveau recherche, publiés ou non, émanant des établissements d'enseignement et de recherche français ou étrangers, des laboratoires publics ou privés. 


\title{
Network Theory-based Analysis of Risk Interactions in Large Engineering Projects
}

\author{
Chao FANG $^{\mathrm{a}^{*}}$, Franck MARLE ${ }^{\mathrm{b}}$, Enrico ZIO ${ }^{\mathrm{c}, \mathrm{d}}$, Jean-Claude BOCQUET ${ }^{\mathrm{b}}$ \\ ${ }^{a}$ Department of Systems Engineering and Engineering Management, City University of Hong Kong, \\ Kowloon, Hong Kong, China \\ ${ }^{b}$ Laboratoire Genie Industriel, Ecole Centrale Paris, 92295, Chatenay-Malabry, France \\ ${ }^{c}$ Chair on Systems Science and the Energetic Challenge, European Foundation for New \\ Energy-Electricite' de France, at Ecole Centrale Paris - Suplec, France \\ ${ }^{d}$ Dipartimento di Energia, Politecnico di Milano, Italy
}

\begin{abstract}
This paper presents an approach based on network theory to deal with risk interactions in large engineering projects. Indeed, such projects are exposed to numerous and interdependent risks of various nature, which makes their management more difficult. In this paper, a topological analysis based on network theory is presented, which aims at identifying key elements in the structure of interrelated risks potentially affecting a large engineering project. This analysis serves as a powerful complement to classical project risk analysis. Its originality lies in the application of some network theory indicators to the project risk management field. The construction of the risk network requires the involvement of the project manager and other team members assigned to the risk management process. Its interpretation improves their understanding of risks and their potential interactions. The outcomes of the analysis provide a support for decision-making regarding project risk management. An example of application to a real large engineering project is presented. The conclusion is that some new insights can be found about risks, about their interactions and about the global potential behavior of the project.
\end{abstract}

Keywords: project risk management, complexity, topological analysis, decision support, network theory

\section{Introduction}

Projects are usually complex and risky. They require the timely accomplishment of a number of activities, carried out by a number of human and material resources. Unexpected conditions or planning errors may lead to failures which can undermine the successful realization of the project on numerous parameters, like time, cost, scope, quality, safety, security, health, and environment. We refer to such events as project risks, when they are identified, analyzed and treated before they occur. Within the same project, the existence of interrelated risks involves that the occurrence of one risk may trigger one or more other risks with potential propagation phenomena like reaction chains, amplification chains or loops. In this sense, in this paper we talk of risk interdependency between two risks. A consequence of a risk is then triggering of another risk and not the direct impact of the risk itself (e.g. on time, scope or cost), which of course exists but is not the focus here. The consequence of this complexity is a lack of capacity to anticipate and control the behavior of the project.

Large engineering projects are facing a growing complexity, in both their structure and context due to the involvement of numerous, diverse and strongly interrelated elements [1-3]. This has sparked research works on the concept of complexity, under two main scientific approaches [4]. The first one, usually known as the field of descriptive complexity, considers complexity as an intrinsic property of a system. For example, Baccarini in [1] considers project complexity through the concepts of technological complexity and organizational complexity. He regards them as the core components of project complexity which he tries to

\footnotetext{
${ }^{*}$ Previously at Laboratoire Genie Industriel, Ecole Centrale Paris, France.
} 
describe exhaustively. The second approach, usually known as the field of perceived complexity, considers complexity as subjective, since the complexity of a system is improperly understood through the perception of an observer. According to Vidal and co-workers, "project complexity is the property of a project which makes it difficult to understand, foresee and keep under control its overall behavior, even when given reasonably complete information about the project system. Its drivers are factors related to project size, project variety, project interdependence and project context" [5].

In this setting, Project Risk Management (PRM) is an indispensable activity for project management, even more for large engineering projects dealing with large stakes and involving interdependent activities and organizations [6-9]. In PRM, risk analysis is used for evaluating and prioritizing risks, essentially with respect to their probability and impact. The outputs of the analysis support decision-making, e.g., in terms of planning response actions and allocating resources.

In practice, the PRM methodologies are often used to analyze risks independently, according to their individual characteristics, with more or less detailed and quantitative approaches, based on experience and/or expertise [10-16]. Various methods can be used to identify causes and effects of a single risk. For instance, Failure Modes and Effects Analysis (FMEA) consists in a qualitative analysis of dysfunction modes followed by a quantitative analysis of their effects, in terms of probability and impact (or severity) [17, 18]; fault tree and cause tree analyses determine the conditions which lead to an event and link them through logical connectors in a tree-structure which clearly displays causes and effects of the particular risk analyzed [19]. Other techniques, like Bayesian networks, system dynamics or Monte-Carlo simulation exist [20-22]. But these methods are focused on risk prioritization considering probability and/or impact of the risks, called Probability-Impact Grid (PIG). Some researchers highlight the weakness related to the fact that important interdependencies are not considered in PRM processes using the PIG approach [23-25]. The importance of modeling interdependencies, and techniques to do this, are presented in several works, whether directly on risk [26, 27] or indirectly on other objects inside the project [28, 29].

In the work here presented, the complexity of interactions among project risks is modeled and represented in terms of a risk network [30]. A topological analysis is then performed on this network, with the aim of giving complementary information, prioritizing some risks and risk interactions in relation to their position in the network. This is relevant because in some cases, it may happen that risks of minor concern are the source of a sequence of propagating effects whose outcome is of far higher severity.

A method based on Design Structure Matrix (DSM) [31] is introduced to build the network of risk interactions. A topological analysis typical of network theory is then performed to identify the characteristics of the resulting risk network. In the last decade, a number of studies have focused on the modeling of complex systems such as critical infrastructures from the standpoint of network theory, to understand how the topological network underlying the system influences its behavior, and eventually its characteristics of stability and robustness to faults and attacks [32]. Topological network analysis has been exploited to serve as a screening tool to identify key components in different types of infrastructure networks, like power transmission systems [33] and railway networks [34] for example. The originality of the work presented in this paper is the tailoring and application of network theory-based topological analysis in the context of project risk management. The application to a real large engineering project enables the usefulness and practicality of the approach to be validated.

The paper is organized as follows. In Section 2, the modeling of project risk network is introduced, with the identification and assessment of risks and risk interactions. Section 3 introduces some topological indicators and explains how the network theory-based topological analysis is performed on the project risk network. An example of application to a tramway implementation project is presented in Section 4. The added value and applications to decision support are discussed in Section 5. Some conclusions are drawn in Section 6, with perspectives on future work. 


\section{Building the structure of project risk network}

To perform the topological analysis for exploring the risk interactions-based properties, the project risk network should be constructed. In the following parts of this section, we introduce the process of building the project risk network structure.

\section{Step 1. Risk identification using classical methods}

Risk identification is usually the first step for project risk analysis, aimed at determining events which could affect project objectives positively or negatively [35]. This paper mainly focuses on the conventional risk events with negative effects. There are a number of classical methods for identifying individual project risks. They are based on analogy [36-38], on heuristics [39, 40] or are analytic [41]. Our study uses directly the risks previously identified by the project manager using these classical methods. The result of these analyses, the project risk list, serves as an input for studying risk interactions. Even if some authors propose an approach to risk dynamics analysis [42], the process is performed with a stable list of risk with stable characteristics.

\section{Step 2. Identification of risk interactions using DSM method}

Identification of risk interactions is the step of determining the cause-effect relationship between risks. This is also the main step for building the project risk network structure. Risk interaction is considered as the existence of a possible precedence relationship between two risks $R_{i}$ and $R_{j}$.

The Design Structure Matrix (DSM) method introduced by Steward [31] has proven to be a practical tool for representing and analyzing relations and dependencies among components in system design $[43,44]$. In our work, we propose to extend the concept of DSM to risks in project management. The interrelations between project objects, such as activities, actors and product components, can facilitate the identification of interrelations between the risks related to these objects. For instance, the project schedule gives information about activity-activity sequence relationships. This enables the relationship between two risks of delay for these activities to be identified. A component-component relationship (whether functional, structural or physical) means that risks, which may be related to product functions, quality, delay or cost, can be linked, since a problem on one component may have an influence on another (budget limits, for instance). In a similar way, the Domain Mapping Matrix (DMM) introduced by Danilovic and Browning [44] and Multiple-Domain Matrix (MDM) introduced by Lindemann, Maurer and Braun [45] are helpful in identifying risk interactions across different domains of the project.

We define the Risk Structure Matrix (RSM), which is a binary and square matrix with entry $R S M_{i j}=1$ when there is a relationship link from $R_{i}$ to $R_{j}$. Figure 1 gives an example of the RSM representation of a network of risks.

When performing the risk interaction identification, new risks may appear, for two reasons. Some are a consequence or cause of other risks already present in the initial list; others are seen as intermediary risks which are useful to explain the link between two or more existing risks. Identification is done on direct cause-effect relationship. However, we ask interviewees whether they think this is a direct link or if new intermediary elements deserve to be included. When there is a dependency between risks R1 and R3 because R1 is linked to $\mathrm{R} 2$ and $\mathrm{R} 2$ is linked to R3, this is called an indirect dependency and there is no need to formalize a dependency between R1 and R3. On the contrary, when there is a link between R1 and R3, but experts realize that there is an intermediary risk, R2, that deserves to be included in the model, then the direct dependency between R1 and R3 is replaced by two direct dependencies, between respectively $\mathrm{R} 1$ and $\mathrm{R} 2$, and $\mathrm{R} 2$ and $\mathrm{R} 3$. 


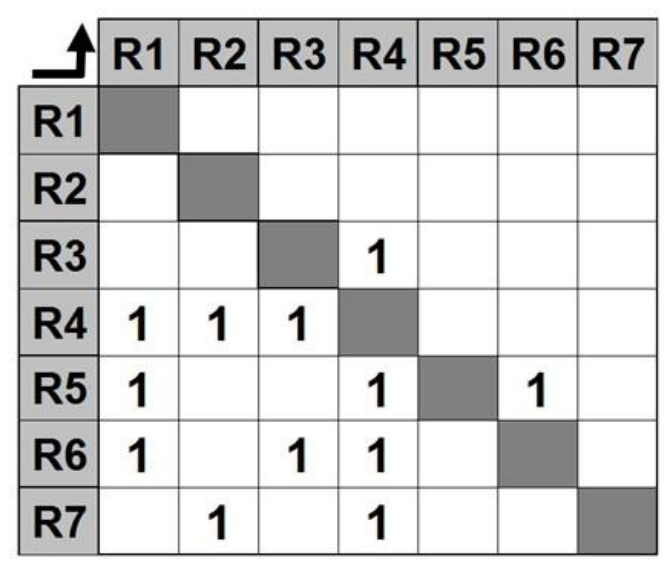

(a) example of RSM

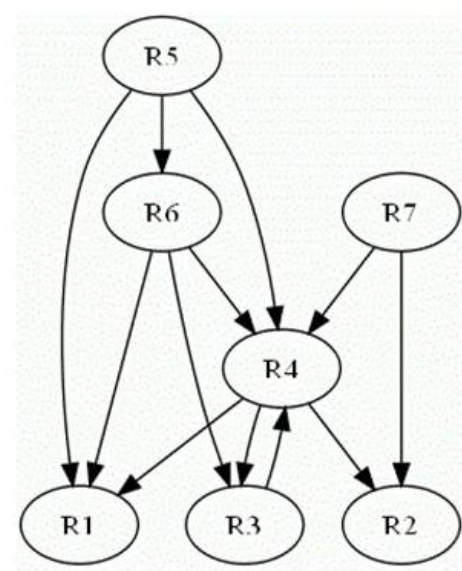

(b) example of project risk network

Figure 1. Illustration of RSM and project risk network (adapted from [30])

We assume that the identified risk interrelationship does not address concerns about the impact of this interaction. In practice, a sanity check is performed: suppose we know that $R_{j}$ declared $R_{i}$ as a cause; if $R_{i}$ did not declare $R_{j}$ as a consequence, then there is a mismatch. Each mismatch is studied and solved, like in analogous works by Sosa, Eppinger and Rowels about interactions between project actors [46].

\section{Step 3. Assessment of risk interactions}

A qualitative assessment is also conducted to screen out some insignificant risk interactions. Based on the established RSM, the weight of each non-zero element in the matrix (identified potential risk interaction) can be assessed during the interviews or meeting with the project manager and/or related experts involved. Direct assessment is made for each potential interaction by one or more experts according to their experience and/or expertise. In this study, a qualitative scale (from 0 to 10) is used for assessing the strength of risk interactions, in terms of cause-effect relationship. For example, the identified risk interactions with the scale below 2 (equal to 0 or 1 ) are considered insignificant and thus are not included in the risk network structure for the subsequent topological analysis. In the process of assessment, different experts may get outcomes with differences. To moderate this kind of confusion and divergence, particular experts are asked to be responsible for several rows and columns in the RSM according to their specialty. Finally, the assessment results from different experts need to be combined and consolidated.

One should be aware of the particularity of a project risk network, as compared to, for example, other physical networks of critical infrastructures, like a power transmission network. A project risk network links elements (nodes of risks), which can possibly be affected by the potential propagation (arcs of risk interactions) of effects of different nature. Vidal and Marle developed a model of defining several types of interactions between risks [47]. The specificity of this network is to involve potential interactions between nodes which are not necessarily related to physical and material characteristics, like delay risk for instance.

\section{Topological analysis of the project risk network}

For the topological analysis of a project risk network, we represent the risk network by a graph $G(N, K)$, in which the identified risks are mapped into $N$ nodes connected by $K$ unweighted arcs. As shown in Figure 1, the risk network is a directed network: each arc from $R_{i}$ to $R_{j}$ represents the fact that there is a directed potential cause-effect link between them. In the jargon of graph theory, the RSM is the adjacency matrix of the risk network [48].

Such representation enables us to study the structural properties of the risk network, by means of some topological indicators tailored to the problem at hand. These indicators can help identifying key factors (risks or risk interactions) and improve the project manager's understanding of the vulnerabilities in the network.

The numbers of nodes and risk natures/domains describe the size and diversity of the risk 
network. The density of the graph can be measured by Eq. (1). Usually some pairs of nodes are disconnected and thus the risk network is not a fully connected graph. There may also be unconnected nodes representing isolated risks, i.e., risks having no identified cause-effect interrelation or negligible cause-effect interrelation with other risks in the system.

$\operatorname{Den}(G)=K / N(N-1)=\sum_{i, j \in G} R S M_{i j} / N(N-1)$

The degree of nodes provides an indication of the local connectivity characteristic of a risk. The number of outgoing arcs is the activity degree of a risk (Eq. (2)) and the incoming arcs give the passivity degree of it (Eq. (3))[49]. These two metrics of degree convey the relationship of a risk with its immediate neighbor risks:

$$
\begin{aligned}
& \operatorname{Deg}_{i}^{A}=\sum_{j \in G} R S M_{i j} \\
& \operatorname{Deg}_{i}{ }_{i}=\sum_{j \in G} R S M_{j i}
\end{aligned}
$$

In order to get further insights on the global connectivity property of the risks, we study the reachability degree of nodes. We introduce the concept of Risk Reachability Matrix (RRM), with $R R M_{i j}=1$ if there exists at least one path from $R_{i}$ to $R_{j}$. Both the shortest path between each pair of risks and the RRM can be obtained using the Floyd's sequential shortest path iterative algorithm [50]. The reachability density defined in Eq. (4) is a measure of the complexity of the risk network based on risk reachability:

$\operatorname{Rea}(G)=\sum_{i, j \in G} R R M_{i j} / N(N-1)$

The number of reachable nodes (Eq. (5)) indicates the number of other risks that a given risk can impact directly and indirectly. The number of possible sources (Eq. (6)) accounts for the fact that the occurrence of a designated risk can possibly originate from many other risks in the network.

$$
\begin{aligned}
& N_{i}{ }^{R}=\sum_{j \in G} R R M_{i j} \\
& N_{i}{ }_{i}=\sum_{j \in G} R R M_{j i}
\end{aligned}
$$

The introduced indicators of reachability degree help us understand the global consequences and sources of a risk, and enable us to classify them into different categories.

In project management, risks are also usually categorized into different domains such as technical, financial and managerial. Further, from the point of view of organization, different risk owners are assigned in charge of one or several risks. The number of interfaces between domains/owners is defined as the number of arcs between each pair of them. In the local sense, the indicators $I_{D_{u v}}^{L}$ and $I_{O_{u v}}^{L}$ defined in Eqs. (7) and (8) below denote the number of local direct interfaces from $D_{u}$ to $D_{v}$ and from $O_{u}$ to $O_{v}$ respectively, where $D_{u}$ and $O_{v}$ stand for domain $u$ and risk owner $v$ :

$$
\begin{aligned}
& I_{D_{u v}}^{L}=\sum_{R_{i} \in D_{u}, R_{j} \in D_{v}} R S M_{i j} \\
& I_{O_{u v}}^{L}=\sum_{R_{i} \in O_{u}, R_{j} \in O_{v}} R S M_{i j}
\end{aligned}
$$

On the other hand, the indicators $I_{D_{u v}}^{G}$ and $I_{o_{u v}}^{G}$ defined in Eqs. (9) and (10) indicate the number of global reachable interfaces from $D_{u}$ to $D_{v}$ and from $O_{u}$ to $O_{v}$ respectively:

$$
I_{D_{u v}}^{G}=\sum_{R_{i} \in D_{u}, R_{j} \in D_{v}} R R M_{i j}
$$


$I_{O_{u v}}^{G}=\sum_{R_{i} \in O_{u}, R_{i} \in O_{v}} R R M_{i j}$

The interface indicators help project managers identify the interconnections between different domains and enhance the intercommunication between correlated counterparts. It notably enables the grouping of risk owners in order to improve coordinated decision-making.

For the purpose of anticipating the potential risk propagation and related needs for protection, another indicator is here introduced. In general network theory, the betweenness centrality [51, 52] is based on the idea that a node or an arc in a network is central if it lies between many other nodes. In a risk network, if a risk node or a risk interaction arc lies in at least one of the paths connecting a pair of other nodes, we count that node or arc as lying between them. The betweenness centrality of $R_{k}$ and the betweenness centrality of the arc from $R_{p}$ to $R_{q}$ can then be calculated by the following equations:

$$
\begin{aligned}
& B_{k}=\sum_{i, j \in G, i \neq j \neq k} R R M_{i k} \text { AN D } R R M_{k j} \\
& B_{p \rightarrow q}=\sum_{i, j \in G, i \neq j \neq p \neq q} R R M_{i p} \text { A N D } R R M_{q j}
\end{aligned}
$$

In practice, project risk networks are often quite sparse, with $K<<N(N-1) / 2$, hence we do not normalize the betweenness centralities by dividing by their possible upper values, i.e., $(N$ $-1)(N-2)$ for nodes and $(N-2)(N-3)$ for arcs. In this way, the betweenness centralities of nodes or arcs denote the number of pairs of risks they lie between. Knowledge of these centralities assists in identifying hubs in the network which play the role of key passages for risk propagation: the project manager should consider how to avoid propagation through these passages by controlling the risks and/or blocking their interactions.

\section{Application to a tramway infrastructure project}

In this Section, we illustrate the application of the proposed approach to a real large engineering project, aimed at building the infrastructure and associated systems of the future tramway in a city with a population of 750000 . Both classical project risk analysis and the proposed network theory-based analysis on the topological structure are carried out.

The project includes the construction and implementation of tramway, equipments, and civil work, with 10 years duration and hundreds of millions $€$ budget. The leading company is a designer and manufacturer of trains, which recently extended its scope by proposing "turn key" projects, including not only the trains, but also the complete infrastructure around the trains. The project thus comprises:

- The construction of a depot to stock trains and to execute their control and maintenance;

- The installation of tracks throughout the city, over land with many steep slopes;

- The delivery of the corresponding trains, including redesign activities if the current version does not fit with the city's specific requirements;

- The establishment of a traffic signaling operating system, which gives priority to the tramway so as to guarantee travel time performance levels.

\subsection{Building the project risk network}

A project risk list is provided by the project manager and its expert team, containing 56 identified risks at the main level, with their name, domain and risk owner information, as shown in Table 1. These potential negative risks are classified according to six domains (22 risks of D1-Technical, 24 risks of D2-Contractual, 6 risks of D3-Financial, 1 risk of D4-Client/Partner/Subcontractor, 2 risks of D5-Project management on construction site, 1 risk of D6-Country). Risk ownership in terms of responsibility is assigned to 11 actors in the project management team. Basic characteristics of risks have been assessed by the project manager and associated experts, as shown in Table 1, including qualitative probability and impact scales, as well as criticality (product of probability and impact).

Identification of the risk interdependencies (by the steps described in Section 2) allows defining the structure of the project risk network, shown in Figure 7. The network is 
comprised of 56 nodes (risks) and 95 arcs (risk interactions), with only 5 unconnected nodes (R8, R11, R15, R23 and R34). For each node, experts were asked to provide information about the potential causes and effects (to explore the row and the column corresponding to the considered risk). In the end, the aggregation of local cause-effect relationship identifications enables to display the global risk network. This enables a final meeting to be organized in which interviewees can propose new nodes and connections in the risk graph. The graph density is equal to 0.0308 , showing that the network is relatively sparse.

The assessment of the existing risk interactions was then performed on a 10-level Likert scale, due to the high expertise of interviewees. Six of the risks which were present in the initial list (R1, R8, R11, R15, R23 and R34) were considered as poorly interrelated with others and possibly negligible for this study. Some difficulties were encountered while performing the assessment. In particular, this step requires the participation of several experts involved in the project since it necessitates a very wide overview of the project elements and stakes. 
Table 1. Project risk list with classical risk characteristics assessment

\begin{tabular}{|c|c|c|c|c|c|c|}
\hline Risk ID & Risk Name & Risk Domain & Risk Owner & $\begin{array}{l}\text { Qualitative Risk } \\
\text { Probability }\end{array}$ & $\begin{array}{l}\text { Qualitative } \\
\text { Risk Impact }\end{array}$ & Criticality \\
\hline 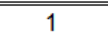 & Safety studies & Technical & 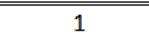 & 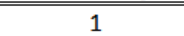 & 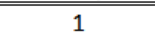 & 1 \\
\hline 2 & $\begin{array}{l}\text { Liquidated damages on intermediate milestone and } \\
\text { delay of Progress Payment Threshold }\end{array}$ & Contractual & 2 & 7 & 8 & 56 \\
\hline 3 & Vehicle storage in another city & Contractual & 1 & 9 & 5 & 45 \\
\hline 4 & Vandalism on site & Contractual & 3 & 1 & 3 & 3 \\
\hline 5 & $\begin{array}{l}\text { Traction/braking function : behaviour in degraded } \\
\text { mode on slope }\end{array}$ & Technical & 1 & 3 & 2 & 6 \\
\hline 6 & New local laws and regulations & Contractual & 1 & 1 & 3 & 3 \\
\hline 7 & Traffic signalling, priority at intersections & Contractual & 4 & 6 & 5 & 30 \\
\hline 8 & $\begin{array}{l}\text { Unclear Interface with the Client, for Infrastructure } \\
\text { equipment }\end{array}$ & Contractual & 5 & 1 & 2 & 2 \\
\hline 9 & Delays due to client late decisions & Contractual & 5 & 9 & 1 & 9 \\
\hline 10 & Travel Time performance & Technical & 4 & 1 & 3 & 3 \\
\hline 11 & Limited Force majeure definition & Contractual & 2 & 1 & 4 & 4 \\
\hline 12 & Operating certificate delay & Contractual & 2 & 9 & 4 & 36 \\
\hline 13 & Reliability \& availability targets & Technical & 4 & 3 & 3 & 9 \\
\hline 14 & Permits \& authorisations & Contractual & 2 & 9 & 2 & 18 \\
\hline 15 & Insurance deductibles & Financial & 6 & 1 & 3 & 3 \\
\hline 16 & Archeological findings & Contractual & 2 & 9 & 3 & 27 \\
\hline 17 & Discrepancies Client / Operator / Concessionaire & Contractual & 7 & 3 & 5 & 15 \\
\hline 18 & Civil Work delay \& continuity & Contractual & 8 & 9 & 4 & 36 \\
\hline 19 & Responsibility of client on Civil Work delay & Contractual & 2 & 9 & 2 & 18 \\
\hline 20 & On board CCTV scope & Technical & 9 & 5 & 1 & 5 \\
\hline 21 & Noise \& vibration attenuation & Technical & 4 & 3 & 6 & 18 \\
\hline 22 & $\begin{array}{l}\text { Potential risks of claim from Civil Work } \\
\text { subcontractor }\end{array}$ & Contractual & 2 & 5 & 5 & 25 \\
\hline 23 & Harmonics level & Technical & 5 & 1 & 2 & 2 \\
\hline 24 & Non compliance contractual Rolling Stock & Technical & 1 & 1 & 6 & 6 \\
\hline 25 & $\begin{array}{l}\text { Non compliance technical specifications Rolling } \\
\text { Stock }\end{array}$ & Contractual & 1 & 3 & 4 & 12 \\
\hline 26 & Exchange risk on suppliers & Financial & 6 & 1 & 3 & 3 \\
\hline 27 & Track installation machine performance & $\begin{array}{l}\text { Client/Partner/Subcontra } \\
\text { ctor }\end{array}$ & 10 & 3 & 2 & 6 \\
\hline 28 & Tax risk on onshore & Financial & 6 & 1 & 2 & 2 \\
\hline 29 & Additional poles overcost for Tramway Company & Contractual & 5 & 9 & 4 & 36 \\
\hline 30 & Overcost due to Security requirements for trains & Technical & 4 & 5 & 4 & 20 \\
\hline 31 & Track insulation & Technical & 9 & 1 & 1 & 1 \\
\hline 32 & Delay for energising & $\begin{array}{l}\text { Project management, } \\
\text { Construction site }\end{array}$ & 5 & 3 & 2 & 6 \\
\hline 33 & Fare collection requirements & Contractual & 7 & 5 & 3 & 15 \\
\hline 34 & Construction safety interfaces & Technical & 3 & 1 & 1 & 1 \\
\hline 35 & Electromagnetic interferences & Technical & 4 & 1 & 2 & 2 \\
\hline 36 & Exchange risk & Financial & 6 & 1 & 2 & 2 \\
\hline 37 & $\begin{array}{l}\text { Risk of partial rejection of our request for EOT } \\
\text { (Extension Of Time) }\end{array}$ & Contractual & 2 & 9 & 7 & 63 \\
\hline 38 & Interface rail / wheel & Technical & 4 & 3 & 2 & 6 \\
\hline 39 & Risk on Certification of our equipement & Country & 11 & 1 & 2 & 2 \\
\hline 40 & OCS installation & $\begin{array}{l}\text { Project management, } \\
\text { Construction site }\end{array}$ & 3 & 7 & 5 & 35 \\
\hline 41 & Banks stop financing the project & Contractual & 2 & 7 & 3 & 21 \\
\hline 42 & $\begin{array}{l}\text { Costs of modifications not covered by EOT } \\
\text { agreement }\end{array}$ & Contractual & 2 & 1 & 4 & 4 \\
\hline 43 & Return profit decrease & Financial & 2 & 9 & 8 & 72 \\
\hline 44 & Extra trains & Contractual & 4 & 1 & 6 & 6 \\
\hline 45 & Pedestrian zones & Technical & 4 & 1 & 2 & 2 \\
\hline 46 & Train performance & Technical & 1 & 3 & 2 & 6 \\
\hline 47 & Waiting time at stations & Contractual & 4 & 5 & 1 & 5 \\
\hline 48 & Depot delay & Technical & 3 & 9 & 2 & 18 \\
\hline 49 & Error in the Survey (topography) & Technical & 4 & 1 & 1 & 1 \\
\hline 50 & Ticketing design delays & Contractual & 7 & 7 & 1 & 7 \\
\hline 51 & Track installation delay & Technical & 3 & 7 & 2 & 14 \\
\hline 52 & Reengineering / Redesign & Technical & 4 & 9 & 2 & 18 \\
\hline 53 & Slabs pouring delay & Technical & 3 & 5 & 1 & 5 \\
\hline 54 & Initial specifications of CW (Civil Work) & Technical & 3 & 5 & 1 & 5 \\
\hline 55 & Available cash flow decrease & Financial & 2 & 9 & 7 & 63 \\
\hline 56 & Rolling stock delivery delay & Technical & 1 & 3 & 1 & 3 \\
\hline
\end{tabular}




\subsection{Classical project risk analysis results}

In Figure 2 the classical project risk analysis results are displayed in a risk probability vs. impact diagram, where each risk identified in Table 1 is represented by a dot. The limits between different criticality classes should be defined a priori, before the risk assessment. For example, risks can be categorized into several levels of criticality, such as critical, high, moderate and low risks. In Figure 2, we only highlight the top ten risks according to their criticality value. The project is based on a contract including many contractual terms involving financial penalties in case of failure, whether on time or quality aspects. Almost every problem is then potentially transformed directly or indirectly into an additional cost and then a profit loss. It is thus not surprising to see that R2 (Liquidated damages), R37 (Rejection of Extension Of Time), R43 (Return profit decrease) and R55 (Available cash flow decrease) are among the most critical risks. Other risks with high criticality are generally related to the final delivery, like R12 (Operating certificate), or some big parts of the project, like R18 (Civil Work delay) and R40 (Operating Center installation).

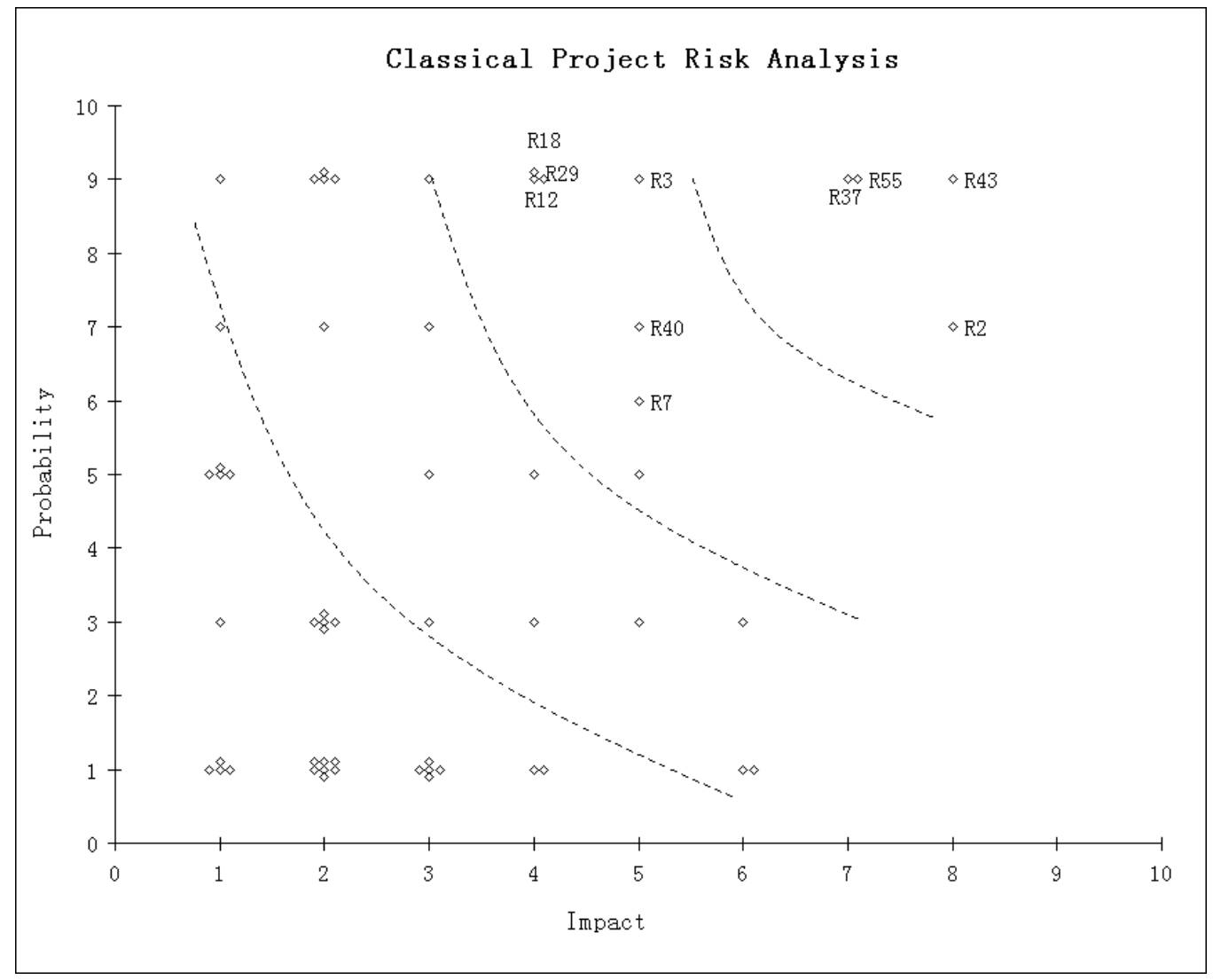

Figure 2. Display of classical project risk analysis results

\subsection{Topological analysis results}

In Figure 3, we display the activity degree and passivity degree of risks, introduced respectively in Eq (2) and $\mathrm{Eq}(3)$, in a matrix diagram. As we can see, a risk can directly impact at most 5 other risks; the passivity degree varies from 0 to 19 , while only several risks have a large number of direct predecessors. For example, R2 (Payment threshold) has 19 immediate predecessor risks. Most risks have 1 or 2 immediate inputs and outputs, implying that the local connectivity of this network is not significant. 


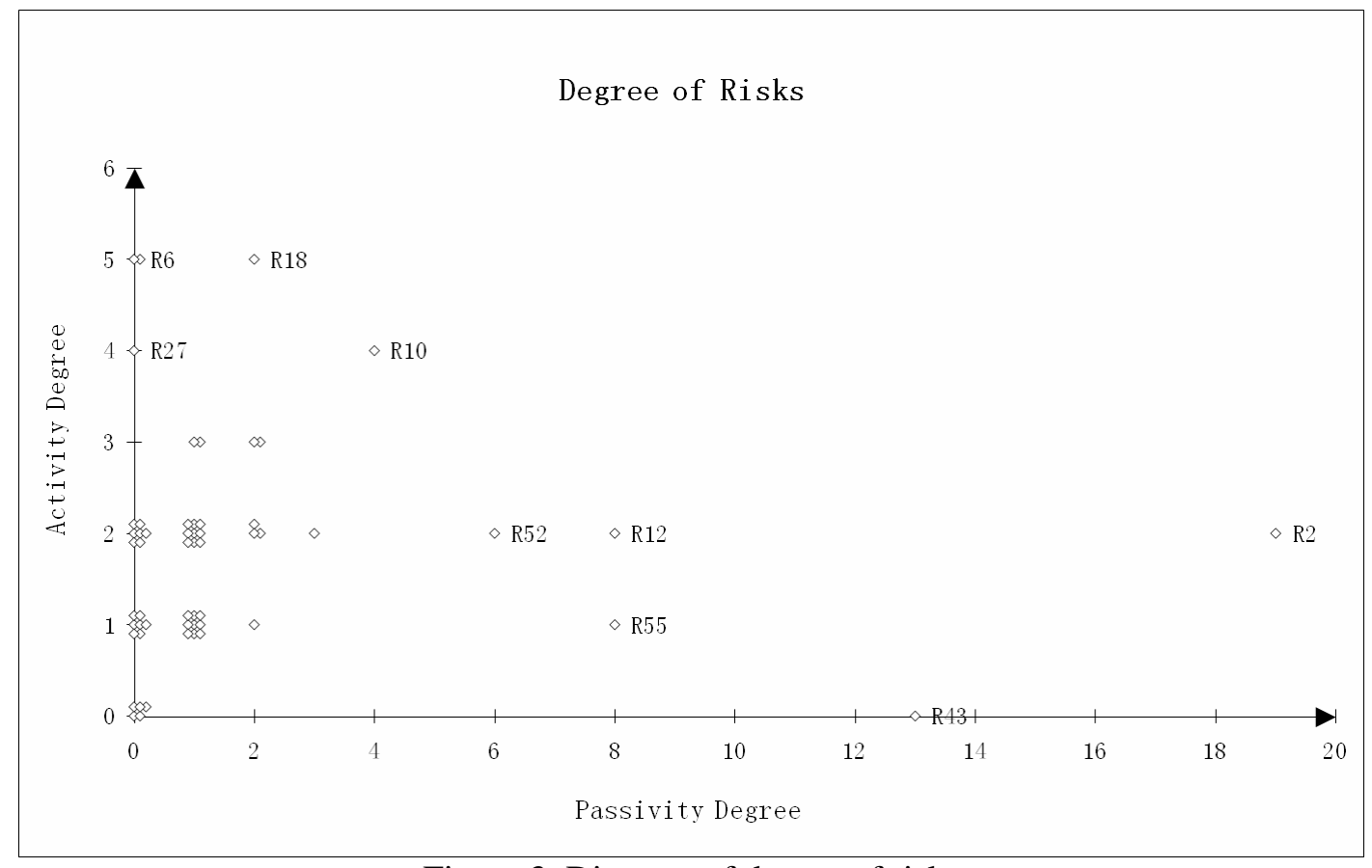

Figure 3. Diagram of degree of risks

Similarly, the reachability degree of risks, namely the number of reachable nodes, and the number of possible sources are displayed in Figure 4 to give a global view of the connectivity property of risks. The reachability density of the network, introduced in $\mathrm{Eq}$ (4), is equal to 0.0854. This shows that the risk network is more complex in the global view of reachability, compared with the low graph density of 0.0308 of the local scale. The roles of these risks in the network are marked with different shapes in Figure 7. Some risks with few predecessors, but that lead to many others are likely to be source risks, such as R6 (New local laws and regulations), R49 (Error in the topography survey), R27 (Track installation machine performance), R16 (Archeological findings), and R19 (Responsibility of client on civil work delay). Some risks with few successors, but which come from many possible sources, are regarded as accumulation risks, often related to project results like financial performance, e.g., R43 (Return profit decrease) and R55 (Available cash flow decrease). Risks in the middle of Figure 4 act as transition risks. Some of these have more sources and fewer reachable risks, and thus are closer to the accumulation risks, such as R2 (Payment threshold), R12 (Operating certificate delay) and R52 (Reengineering / Redesign); some others are closely related to the source risks, for example, R5 (Traction/braking function: behavior in degraded mode on slope) and R18 (Civil work delay \& continuity); other risks like R10 (Travel time performance), R13 (Reliability \& availability targets) and R39 (Risk on certification of equipment) have approximately equal number of possible sources and reachable nodes. This classification of risks depending of their respective number of inputs and outputs is useful for assisting the project manager in deciding how to treat them, independently of their individual assessment. 


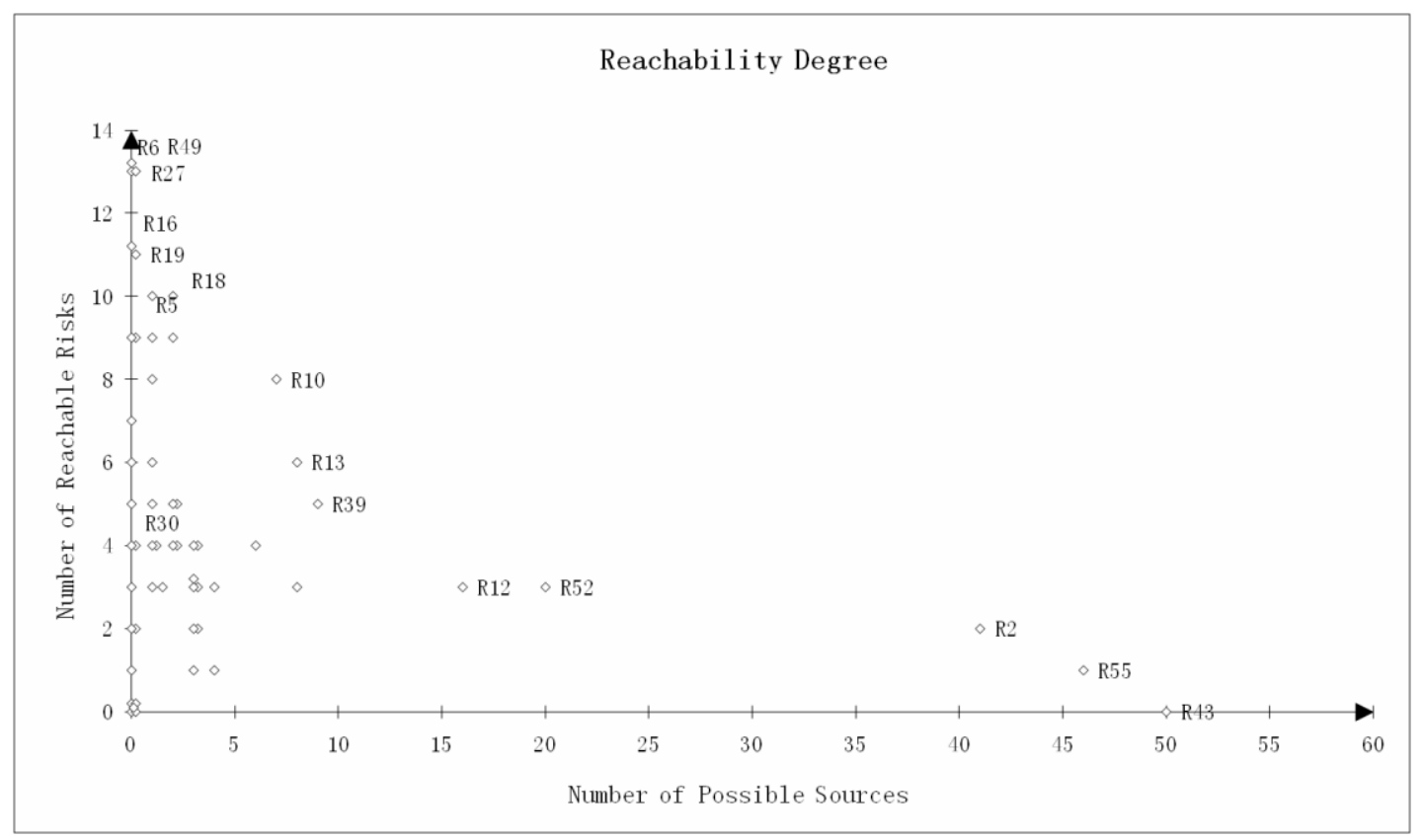

Figure 4. Diagram of reachability degree of risks

Figures 5 and 6 show the number of interfaces between risk domains and owners respectively, from both local and global points of view. Since most risks are belonging to D1-Technical, D2-Contractual and D3-Financial, a large amount of interactions are related to them. In Figure 5, we can see that a large proportion of direct connections are inside a domain (Figure 5(a)). However, many interfaces between different domains have emerged in the global vision (Figure 5(b)). For instance, D1-Technical risks will indirectly cause more contractual and financial risks in D2 and D3; risks from D4-Client/Partner/Subcontractor, D5-Project management on construction site and D6-Country have no direct influence on financial risks but will reach them after propagation of several steps.

\begin{tabular}{lrrrrrrr} 
Local & D1 & D2 & D3 & D4 & D5 & D6 \\
\hline D1 & 13 & 16 & 4 & 0 & 1 & 1 \\
D2 & 9 & 23 & 11 & 0 & 1 & 1 \\
D3 & 0 & 0 & 6 & 0 & 0 & 0 \\
D4 & 2 & 2 & 0 & 0 & 0 & 0 \\
D5 & 0 & 3 & 0 & 0 & 0 & 0 \\
D6 & 1 & 1 & 0 & 0 & 0 & 0
\end{tabular}

(a) local vision

\begin{tabular}{lrrrrrrr} 
Global & D1 & D2 & D3 & D4 & D5 & D6 \\
\hline D1 & 28 & 40 & 40 & 0 & 1 & 6 \\
D2 & 25 & 44 & 42 & 0 & 3 & 3 \\
D3 & 0 & 0 & 6 & 0 & 0 & 0 \\
D4 & 5 & 6 & 2 & 0 & 0 & 0 \\
D5 & 0 & 3 & 4 & 0 & 0 & 0 \\
D6 & 1 & 2 & 2 & 0 & 0 & 0
\end{tabular}

(b) global vision

Figure 5. Interfaces between risk domains

Similarly, many indirect interfaces between risk owners have appeared in Figure 6(b). We find that the risk owner $\mathrm{O} 2$ receives impacts from each of the other owners, and he/she should be more aware of the noticeably increased potential influences from several ones like O1 and O4. Some risk owners cannot identify the direct impact from other actors, but they should foresee and be prepared for the propagated consequences. For instance, the interfaces in the cell $\mathrm{O} 2$ to $\mathrm{O} 3$ have increased from 0 to 6. 


\begin{tabular}{|c|c|c|c|c|c|c|c|c|c|c|c|}
\hline ocal & 01 & 02 & & & 05 & 06 & 07 & 08 & 09 & 010 & 11 \\
\hline 01 & 2 & 4 & 0 & 6 & 0 & 0 & 1 & 0 & 0 & 0 & 1 \\
\hline O2 & 0 & 15 & 0 & 0 & 0 & 0 & 0 & 2 & 0 & 0 & 0 \\
\hline O3 & 1 & 9 & 0 & 2 & 0 & 0 & 0 & 0 & 0 & 0 & 0 \\
\hline O4 & 2 & 11 & 1 & 6 & 1 & 0 & 0 & 0 & 1 & 0 & 1 \\
\hline 05 & 0 & 5 & 0 & 1 & 0 & 0 & 0 & 0 & 0 & 0 & 0 \\
\hline 06 & 0 & 5 & 0 & 0 & 0 & 0 & 0 & 0 & 0 & 0 & 0 \\
\hline 07 & 0 & 1 & 0 & 0 & 1 & 0 & 2 & 0 & 0 & 0 & 0 \\
\hline 08 & 0 & 1 & 3 & 0 & 1 & 0 & 0 & 0 & 0 & 0 & 0 \\
\hline 09 & 0 & 1 & 2 & 0 & 0 & 0 & 0 & 0 & 0 & 0 & 0 \\
\hline 010 & 0 & 2 & 1 & 1 & 0 & 0 & 0 & 0 & 0 & 0 & 0 \\
\hline 011 & 0 & 1 & 0 & 1 & 0 & 0 & 0 & 0 & 0 & 0 & 0 \\
\hline
\end{tabular}

(a) local vision

\begin{tabular}{|c|c|c|c|c|c|c|c|c|c|c|c|c|}
\hline Iobal & 01 & 02 & 03 & 04 & 05 & 06 & 07 & 0 & & 09 & 010 & 011 \\
\hline D1 & 2 & 28 & c & 15 & ( & ) & 0 & 1 & 0 & 0 & 0 & 3 \\
\hline 2 & 2 & 27 & 6 & 2 & 2 & 2 & 0 & 0 & 2 & 0 & C & 0 \\
\hline 33 & 1 & 19 & C & 2 & ( & 0 & 0 & 0 & 0 & 0 & . & \\
\hline 4 & 4 & 44 & 2 & 22 & ? & 1 & 0 & 0 & 0 & 1 & . & \\
\hline 05 & 0 & 12 & 0 & 1 & 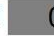 & 0 & 0 & 0 & 0 & 0 & 0 & 0 \\
\hline 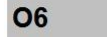 & 0 & 5 & 0 & 0 & ( & 0 & 0 & 0 & 0 & 0 & 0 & 0 \\
\hline 7 & 0 & 11 & 0 & 0 & 2 & 2 & 0 & 3 & 0 & 0 & 0 & 0 \\
\hline 8 & . & 4 & 3 & 1 & 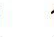 & 1 & 0 & 0 & 0 & 0 & 0 & 0 \\
\hline 99 & 0 & 6 & 2 & 1 & 1 & 0 & 0 & 0 & 0 & 0 & 0 & 0 \\
\hline 210 & 2 & 7 & 1 & 2 & ( & 0 & 0 & 0 & 0 & 1 & 0 & 0 \\
\hline 011 & 0 & 4 & 0 & 1 & 1 & 0 & 0 & 0 & 0 & 0 & 0 & \\
\hline
\end{tabular}

(b) global vision

Figure 6. Interfaces between risk owners

Table 2 displays the top five nodes and top five arcs with the highest betweenness centrality, and these are also highlighted in Figure 7 (respectively with grey-filled nodes and bold arcs). Risks with the highest betweenness centrality such as R2 (Payment threshold) and R52 (Reengineering / Redesign) act as hubs connecting many pairs of risks. We can see that the most important arcs are related to these top risks. R10 and R13 are the sources of many events and should be treated with caution, mainly with preventive actions or with confinement actions (arcs from R10 or from R13, especially the R10->R13 arc). Confinement actions are quite new in the project management field, where the actions are focused on risk nodes only.

Table 2. The top risks and interactions according to the betweenness centrality

\begin{tabular}{ccccc}
\hline Rank & Risk ID & $\begin{array}{c}\text { Betweenness } \\
\text { centrality }\end{array}$ & Arc ID & Betweenness centrality \\
\hline 1 & R2 & 82 & R10->R13 & 42 \\
2 & R52 & 60 & R2->R55 & 41 \\
3 & R10 & 56 & R13->R39 & 40 \\
4 & R12 & 48 & R52->2 & 40 \\
5 & R13 & 48 & R12->R2 & 32 \\
\hline
\end{tabular}




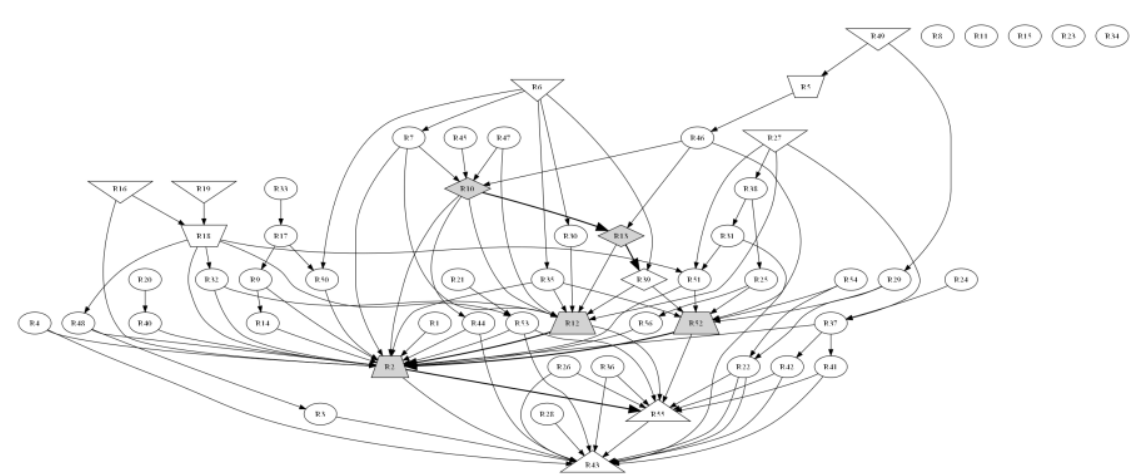

Figure 7. Structure of the project risk network (with highlighted important risks and interactions) 


\section{Discussion of the results}

The results obtained in the previous application show the usefulness of the topological network-based analysis for large engineering project risk management. The proposed indicators provide the project manager with useful information for understanding risks and their relationships at both local and global scales.

Several critical risks identified by classical project risk analysis are confirmed by the topological analysis to play an important role in the risk network, for instance, the financial risks like R43 and R55. In addition, more is learned about the relationship among risks in the network. Some new key risks are highlighted by the topological analysis, which are supplement results to classical analysis. The risks identified can be classified into different categories according to their positions in the network. This information enables planning by the project manager of complementary mitigation actions suitable for the particular type of risks. These actions are included in the global risk response plan, as part of the project plan, to adequately manage the required resources, budget and time. Without this topological analysis, the project manager would not have decided to plan actions on these specific risks. For example, many source risks like R16, R19, R6, R27, and R49 were not identified as critical in the classical analysis. Paying attention to these risks at the beginning of the project may help avoid many problems arising at later stages. Preventive or confinement actions are more likely to be effective for this kind of risks. Corrective or protection actions are often designed for accumulation risks like R43 and R55 to reduce losses. Avoidance or mix of strategies can be applied to transition risks for mitigating the risk propagation. Without this approach, the project manager would not have decided to launch actions on these specific risks, highlighted for topological reasons.

Moreover, important interactions of risks with a high betweenness centrality value are also identified. Resolving these will mitigate the potential propagation between many risks in the network. For example, cutting the arc R10->R13 would separate two parts of the network, so that if the internal risks of one part are correctly managed, no risk of external origin needs to be considered. This is important since internal risks are generally easier to influence and to manage for the owners. Allocating resources and conducting actions on these key risks or interactions can be efficient for mitigating the propagation phenomena and reducing the overall risk exposure.

As an example, we tested a combination of four actions: 1) avoid R12 (Operating certificate delay); 2) avoid R27 (Track installation machine performance); 3) avoid R52 (Reengineering / redesign); and 4) cut the link between R10 (Travel time performance) and R13 (Reliability and availability targets). Applying these actions translates into removing the nodes (R12, R27, and R52) and the arc (R10->R13) in the risk network. Note that only R12 is in the top-ten list of critical risks according to classical project risk analysis. R12 is a transition risk with many causes and only two, but important direct consequences which are financial risks of R2 and R55. R27 is low in terms of classical criticality, but is a source of numerous and important risks, so it may be worthy to use a non-innovative but non-risky track installation machine, in order to estimate with more reliability the duration of track installation activity. R52 is a product-related risk, depending on multiple causes related to the train performance, the customer requirements and the interface rail-wheel. In order to prevent this risk, a more robust requirement definition should be made at the beginning of the project, including the specificities of the project (the city topography and the special needs of the customer). Of course this has to be done for every project, but in this case we contend that a particular effort should be put on the reliability of the initial product requirements, because of their multiple consequences. Finally, we propose to act on the link between R10 and R13, which is quite specific to a topological analysis, since we do not act on nodes, but on one arc. We do not avoid the problem caused by R10 and its other consequences, which are mainly related to customer and contract, but we avoid propagation to another part of the network, where technical and product-related risks could have been activated. It is feasible to cut the transition between the two risks, since there are complementary means to reach reliability and availability targets (train size, train number) without redesigning the train and delaying the delivery of operating certificate. Further work will integrate the cost of actions and make the balance with the benefits of risk reduction. To conclude, all the proposed actions are feasible : three of them come from the topological analysis whereas only one could be identified through classical analysis.

By undertaking the proposed actions, the graph density (Eq (1)) has been reduced from 0.0308 to 0.0265 (by $14.0 \%$ ), and the reachability density ( $\mathrm{Eq}(4)$ ) of the network has been reduced from 0.0854 to 0.0679 (by 20.5\%). The new top five risks and interactions with the highest betweenness centrality are given in Table 3 . Compared with Table 2, we can see that the ranking has changed and the values of betweenness centrality have significantly decreased. The change of the risk network structure is shown in Figure 8. 
Table 3. The top betweenness centralities after taking actions

\begin{tabular}{ccccc}
\hline Rank & Risk ID & $\begin{array}{c}\text { Betweenness } \\
\text { centrality }\end{array}$ & Arc ID & Betweenness centrality \\
\hline 1 & R2 & 64 & R2->R55 & 32 \\
2 & R55 & 39 & R10->R44 & 21 \\
3 & R10 & 28 & R18->R48 & 8 \\
4 & R44 & 24 & R46->R10 & 8 \\
5 & R18 & 16 & R5->R46 & 7 \\
\hline
\end{tabular}

Also, the interface degree between domains/owners (Eqs (7) and (8)) gives the project manager knowledge of how to improve the structure of organization. Reassignment can be conducted so as to reduce the interfaces between different owners. In other words, closely related risks should be assigned when possible to the same owner, in order to mitigate the risk of information asymmetry or non-communication, and to reduce the cost of communication. These reassignments are identified through different sources. First, the right part of Figure 6 gives global information on the direct and indirect interfaces between owners. For instance, owners $\mathrm{O} 2$ and $\mathrm{O} 4$ are strongly related with indirect links, which means that their relation in terms of communication and coordination should be well formalized. Second, the potential chains or pieces of the network with several interrelated risks and some of the highlighted nodes and arcs (Figure 8) that deserve particular attention for topological reasons (Table 3) assist in identifying more effective local reassignments. For a given couple, triplet or group of risks, decisions have to be made on the basis of the existing assignments (Table 1). It depends on the number of actors currently involved and on their skills, in terms of capacity to become the owner of the designated risk. For example, in order to get fewer people involved in potential propagation chains (Figure 8), we can reassign the ownership of:

- risk R18 to actor O2 (instead of O8), since O2 is already the owner of R16 and R19.

- risk R32 to actor O3 (instead of O5), since O3 is already the owner of R51 and R48. It permits also to have only one human interface between $\mathrm{O} 2$ and $\mathrm{O} 3$ for managing the interactions between several risks.

- risk R5 and R46 to actor O4 (instead of O1), thus actor O4 is in charge of managing several risks potentially triggering R10, which is an important hub in the technical area of train performance and customer satisfaction. 


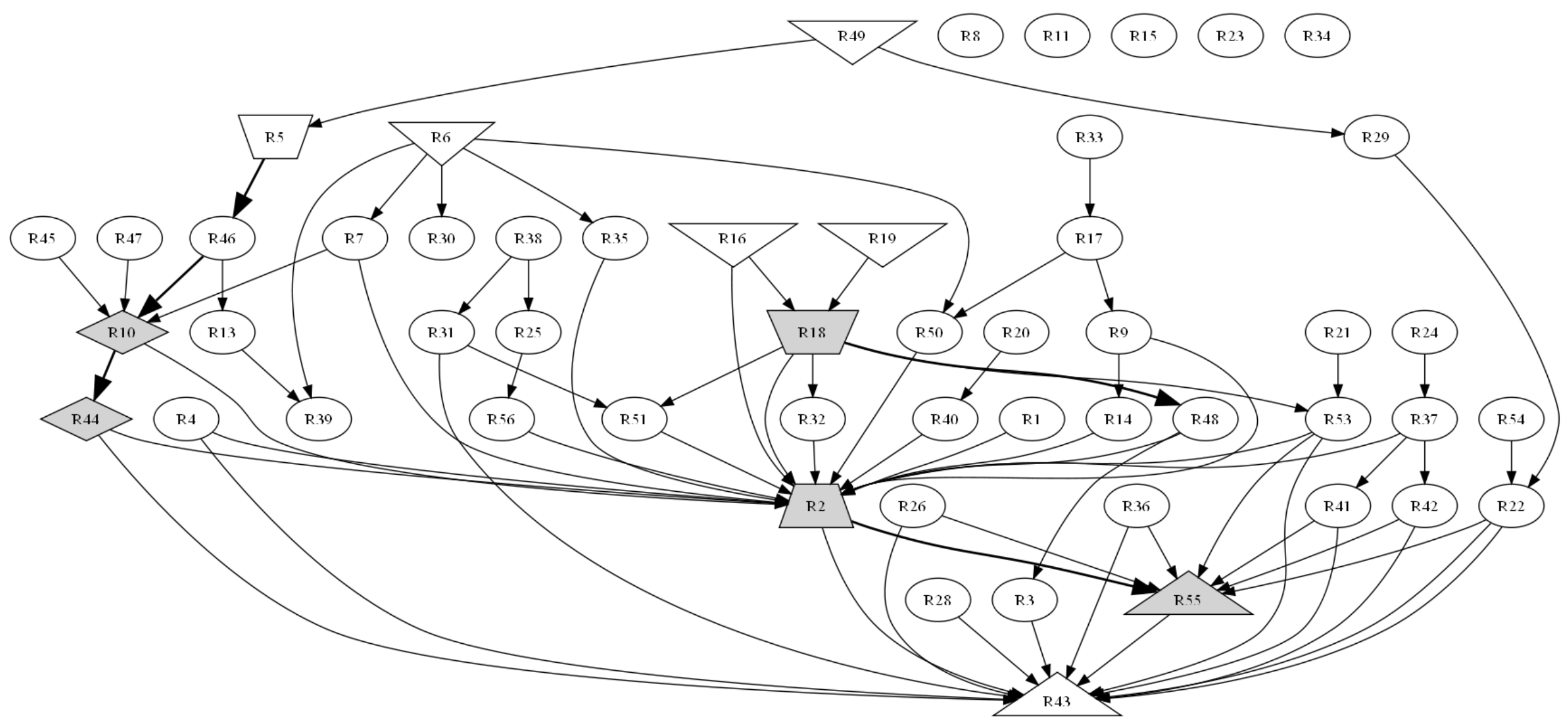

Figure 8. Structure of the project risk network after taking actions 


\section{Conclusions and perspectives}

This paper presents an original network theory-based analysis of interconnected risks in large engineering projects. Network theory indicators are specifically tailored to project risk analysis, in an effort to complement the classical approach with respect to modeling the complexity of interdependent risks. A realistic application on a tramway implementation project is performed with the involvement of the project manager and the team of experts. The results obtained show that the topological analysis by network theory adds value to the classical project risk analysis, in identifying both the important risks and the important risk interactions with respect to their role in the network behavior. This gives additional information for the next step of decision-making, since risks may be considered important for criticality of their impact and/or topological reasons. With respect to the latter, a risk taken individually may be non-critical, but through interactions could become the source of other risks, including some critical ones. Based on the analysis outcomes, a combination of feasible risk mitigation actions are performed on the risk network and the results illustrate the effectiveness of using network theory for project risk analysis. The method is expected to be applicable to a wide set of engineering projects for decision support, including allocating resources for risk mitigation and reassigning risk owners.

In this contribution, only conventional negative project risks have been studied. In a future work, also positive risks and interactions with positive effects could be taken represented and modeled in the project risk network. Moreover, interdependencies coming from the upper organization levels (i.e. functions, programs or projects portfolio, and enterprise) or from external common cause of failures (e.g. the global financial crisis that impacts on both the main contractor and its s hubcontractors) could be included, as they can be relevant and critical sources of risk interdependencies.

In practice, the risks may be formulated with an unclear distinction of the event, its cause and/or its effect. Some risk labels may contain different events, like "risk of having this problem because of this source": this should be divided into two interrelated risks, respectively the event and the source. Moreover, some risks may also be related to the same object, but described by different parameters. For instance, if we have for the same activity three risks related to time, scope and cost parameters, this description is justified if and only if we find individual interactions with other risks (related to other activities, product components, product functions, project objectives, or human resources) which require to have this level of detail. Otherwise, a single risk related to "problems in the activity" is enough. Work is ongoing to determine the proper level of details and the way to formulate risks in less ambiguous ways.

Furthermore, we have assumed that the project risk network is static, namely all the risks and their interdependencies do not change along the progress of the project. However, more research is needed to analyze the dynamics of the network of interacting risks. The risk network should be monitored and periodic reviews conducted, which may lead to the identification of new risks, disappearance of some risks, update of analysis results, and evaluation of the effectiveness of the implemented actions.

\section{Acknowledgement}

The work described in this paper was partially supported by a grant from City University of Hong Kong (Project No.9380058).

\section{References}

[1] Baccarini D. The concept of project complexity - a review. International Journal of Project Management. 1996;14:201-4.

[2] Chu D, Strand R, Fjelland R. Theories of complexity - Common denominators of complex systems. Complexity. $2003 ; 8$.

[3] Corbett LM, Brockelsby J, Campbell-Hunt C. Tackling industrial complexity. Cambridge: Cambridge: Institute for Manufacturing; 2002.

[4] Schlindwein SL, Ison R. Human knowing and perceived complexity: implications for systems practice. Emergence: Complexity and Organization. 2004;6:27-32.

[5] Vidal LA, Marle F, Bocquet JC. Using a Delphi process and the Analytic Hierarchy Process (AHP) to evaluate the complexity of projects. Expert Systems with Applications. 2011;38:5388-405.

[6] Eckert C, Clarkson PJ, Zanker W. Change and customisation in complex engineering domains. Research in 
Engineering Design. 2004;15:1-21.

[7] Kloss-Grote B, Moss MA. How to measure the effectiveness of risk management in engineering design projects? Presentation of RMPASS: a new method for assessing risk management performance and the impact of knowledge management—including a few results. Research in Engineering Design. 2008;19:71-100.

[8] Chapman C, Ward S. Why risk efficiency is a key aspect of best practice projects. International Journal of Project Management. 2004;22:619-32.

[9] Royer PS. Risk management: The undiscovered dimension of project management. Project Management Journal. 2000;31:6-13.

[10] El-Sayegh SM. Risk assessment and allocation in the UAE construction industry. International Journal of Project Management. 2008;26:431-8.

[11] Faber MH, Kroon IB, Kragh E, Bayly D, Decosemaeker P. Risk assessment of decommissioning options using Bayesian networks. Journal of Offshore Mechanics and Arctic Engineering. 2002;124:231.

[12] Garvey P, Lansdowne ZF. Risk matrix: an approach for identifying, assessing, and ranking program risks. Air Force journal of logistics: vol22_no1. 2002:18.

[13] Hastak M, Shaked A. ICRAM-1: Model for international construction risk assessment. Journal of Management in Engineering. 2000;16:59-69.

[14] Hillson D, Grimaldi S, Rafele C. Managing project risks using a cross risk breakdown matrix. Risk Management. 2006:61-76.

[15] Cagno E, Caron F, Mancini M. A multi-dimensional analysis of major risks in complex projects. Risk Management. 2007;9:1-18.

[16] Cagno E, Caron F, Mancini M. Analysis of Major Risks in Complex Projects: The Risk Cube. International Conference on Industrial Engineering Theory, Applications and Practice. Nagoya, Japan. 2006.

[17] Bowles J. The New SAE FMECA Standard. In: IEEE, editor. PROCEEDINGS Annual RELIABILITY and MAINTAINABILITY Symposium1998.

[18] MIL-STD-1629. Procedures for performing FMECA. 1998.

[19] Pahl G, Beitz W, Feldhusen J, Grote K. Engineering Design - A Systematic Approach. 3rd ed: Springer; 2007.

[20] Lewis MA. Cause, consequence and control: towards a theoretical and practical model of operational risk. Journal of Operations Management. 2003;21:205-24.

[21] Neil M, Fenton N, Tailor M. Using Bayesian networks to model expected and unexpected operational losses. Risk Analysis. 2005;25:963-72.

[22] Williams T, Eden C, Ackermann F, Tait A. The effects of design changes and delays on project costs. Journal of the Operational Research Society. 1995:809-18.

[23] Chapman C, Ward S. How to manage project opportunity and risk: Why uncertainty management can be a much better approach than risk management. Chichester, Sussex: John Wiley \& Sons Ltd.; 2011.

[24] Cox Jr AT. What's wrong with risk matrices? Risk Analysis. 2008;28:497-512.

[25] Hubbard DW. The failure of risk management: why it's broken and how to fix it. New jersey: John Wiley \& Sons Inc; 2009.

[26] Allan N, Yin Y, Cantle N. Modeling the Interconnectivity of risks in ERM. 2008.

[27] Raz T, Michael E. Use and benefits of tools for project risk management. International Journal of Project Management. 2001;19:9-17.

[28] Newell S, Goussevskaia A, Swan J, Bresnen M, Obembe A. Interdependencies in complex project ecologies: the case of biomedical innovation. Long Range Planning. 2008;41:33-54.

[29] Staudenmayer NA. Managing multiple interdependencies in large scale software development projects: Massachusetts Institute of Technology; 1721.

[30] Fang C, Marle F. A simulation-based risk network model for decision support in project risk management. Decision Support Systems. 2012;52:635-44.

[31] Steward D. The Design Structure Matrix: a method for managing the design of complex systems. IEEE Transactions in Engineering Management. 1981;28:71-4.

[32] Zio E. From complexity science to reliability efficiency: a new way of looking at complex network systems and critical infrastructures. International journal of critical infrastructures. 2007;3:488-508.

[33] Eusgeld I, Kröger W, Sansavini G, Schläpfer M, Zio E. The role of network theory and object-oriented modeling within a framework for the vulnerability analysis of critical infrastructures. Reliability Engineering \& System Safety. 2009;94:954-63.

[34] Sen P, Dasgupta S, Chatterjee A, Sreeram PA, Mukherjee G, Manna SS. Small-world properties of the Indian railway network. Physical Review E. 2003;67:036106.

[35] PMI SC. A guide to the project management body of knowledge (PMBOK) (2008 ed.). Newton Square, PA, USA. : Project Management Institute.; 2008.

[36] Smith P, Merritt G. Proactive Risk Management. Controlling uncertainty in product development. New York: Productivity Press; 2002.

[37] Riek R. From experience: Capturing hard-won NPD lessons in checklists. The Journal of Product Innovation 
Management. 2001;18:301-13.

[38] Patterson FD, Neailey K. A risk register database system to aid the management of project risk. International Journal of Project Management. 2002;20:365-74.

[39] Chapman RJ. The controlling influences on effective risk identification and assessment for construction design management. International Journal of Project Management. 2001;19:147-60.

[40] Kerzner H. Project management: A systems approach to planning, scheduling and controlling New York: John Wiley \& Sons. 1998.

[41] Shimizu H, Noguchi H. Reliability problem prevention method for automotive components-development of GD'3' activity and DRBFM method for stimulating creativity and visualizing problems. Transaction of Society of Automotive Engineers of Japan, . 2005;36(4):163-8.

[42] Cagno E, Caron F, Mancini M. Dynamic analysis of project risk. International Journal of Risk Assessment and Management. 2008;10:70-87.

[43] Browning T. Applying the design structure matrix to system decomposition and integration problems: a review and new directions. IEEE Transactions in Engineering Management. 2001;48:292-306.

[44] Danilovic M, Browning T. Managing complex product development projects with design structure matrices and domain mapping matrices. International Journal of Project Management. 2007;25:300-14.

[45] Lindemann U, Maurer M, Braun T. Structural complexity management: An approach for the field of product design: Springer Verlag; 2008.

[46] Sosa M, Eppinger S, Rowles C. The misalignment of product architecture and organizational structure in complex product development. Management Science. 2004;50:1674-89.

[47] Vidal L, Marle F. Understanding project complexity: implications on project management. Kybernetes, the International Journal of Systems, Cybernetics and Management Science. 2008.

[48] West DB. Introduction to graph theory: Prentice Hall Upper Saddle River, NJ; 2001.

[49] Kreimeyer MF. A structural measurement system for engineering design processes: Universitätsbibliothek der TU Mnchen; 2010.

[50] Floyd RW. Algorithm 97: shortest path. Communications of the ACM. 1962;5:345.

[51] Freeman LC. A set of measures of centrality based on betweenness. Sociometry. 1977;40:35-41.

[52] Guimera R, Amaral LAN. Modeling the world-wide airport network. The European Physical Journal B-Condensed Matter and Complex Systems. 2004;38:381-5. 